\title{
Metabolomics revealed the toxicity of cationic liposomes in HepG2 cells using UHPLC-Q-TOF/MS and multivariate data analysis
}

Jing Yu ${ }^{a, 1}$, Hai Zhang ${ }^{b, 1}$, Ying $\mathrm{Li}^{a}$, Sen Sun ${ }^{a}$, Jie Gao ${ }^{c}$, Yanqiang Zhong ${ }^{c}$, Duxin Sun ${ }^{d}, *$, Guoqing Zhang ${ }^{a}$ *

${ }^{1}$ These authors contributed equally to this work.

$\square$ Guoqing Zhang

E-mail: gqzhang@smmu.edu.cn

Telephone/Fax: +86-21-81875571

$\triangle$ Duxin Sun

E-mail: duxins@umich.edu

Telephone/Fax: +1 7346158740 / +1734615 6162

aDepartment of Pharmacy, Eastern Hepatobiliary Surgery Hospital, Shanghai 200438, China

${ }^{b}$ Department of Pharmacy, Shanghai First Maternity and Infant Hospital, Tong ji University School of Medicine, Shanghai 201204, China

'Second Military Medical University School of Pharmacy, Shanghai 200433, China

dDepartment of Pharmaceutical Science, College of Pharmacy, University of Michigan, Ann Arbor, MI 48109, USA

\begin{abstract}
Cationic liposomes (CLs) are novel non-viral vectors widely used for delivering drugs or genes. However, applications of CLs are largely hampered by their cytotoxicity, partly because the potential mechanism underlying the cytotoxicity of CLs remains unclear. The aim of the present study was to explore the underlying mechanism of cytotoxicity induced by CLs on HepG2 cells. Differential metabolites were identified and quantified using ultra-liquid chromatography quadrupole time-of-flight mass spectrometry (UHPLC-Q-TOF/MS). The toxicity of CLs on HepG2 cells was evaluated by multivariate data analysis and statistics. Additionally, CCK-8 assay, heatmap, pathway and co-expression network were carried out to explore the relations between the metabolites and the pathways. The results showed a dose-dependent toxic effect of CLs on
\end{abstract}

This is the author manuscript accepted for publication and has undergone full peer review but has not been through the copyediting, typesetting, pagination and proofreading process, which may lead to differences between this version and the Version of Record. Please cite this article as doi: $10.1002 /$ bmc.4036

This article is protected by copyright. All rights reserved. 
HepG2 cells, with an $I_{50}$ value of $119.9 \mu \mathrm{g} / \mathrm{ml}$. Multivariate statistical analysis identified 42 potential metabolites between CLs-exposure and control groups. Pathway analysis showed significant changes in pathways involving amino acid metabolism, energy metabolism, lipid metabolism and oxidative stress in CLs-exposure group vs. control group. Metabolites related to the above-mentioned pathways included phenylalanine, methionine, creatine, oxalacetic acid, glutathione (GSH), oxidized glutathione (GSSG), choline phosphate and several unsaturated fatty acids, indicating that cells were disturbed in amino acid metabolism, energy and lipid supply when CLs exposure-induced injury occurred. It is concluded that CLs may induce cytotoxicity by enhancing ROS in vitro, affect the normal process of energy metabolism, disturb several vital signaling pathways and finally induce cell death.

Keywords: cationic liposome, UHPLC-Q-TOF/MS, metabolomics, cytotoxicity

\section{Introduction}

Non-viral vectors have been widely used as carriers of drug delivery systems in the treatment of cancer (Andresen et al. 2005). Among the non-viral vectors currently available, cationic liposomes (CLs) are considered most promising in that they transfer drugs through cellular membranes so that they can form electrostatic complexes with plasmid DNA. Various cationic lipids have been synthesized and tested for use in non-viral gene delivery (Filion and Phillips 1997). Although the transferring efficacy of CLs is substantially lower than that of viral vectors, CLs have some unique advantages including biodegradability, design flexibility and cell targeting capability (Gujrati et al. 2014; Cortesi et al. 2015). On the other hand, CLs also have some unneglectable disadvantages, including high cytotoxicity and other adverse effects (Kagan et al. 2005), which greatly hamper wider applications of CLs. Meanwhile, the potential mechanism underlying cytotoxicity of CLs has not been well defined.

There are wide variations in toxicity of non-gene-carrying CLs from different human cells. The capacity for nonspecific toxicity due to CLs themselves should be carefully considered when drug-containing liposomes are to be administered in humans (Romoren et al. 2004). On the one hand, the presence of high concentrations of negative charged plasma proteins may affect the surface charge of CLs, or even aggregate CLs into micelles, causing significant cellular toxicity in the circulation process (Filion and Phillips 1997). At the same time, some studies in the literature pointed out that the activity of cell membranes may disturb the integrity and the membrane function of cells or subcellular compartments, causing toxicity (Knudsen et al. 2015). Generally, CLs are mainly composed of natural phospholipids containing unsaturated fatty acids, which are 
easily oxidized, thus reducing the liquidity. Aggregation of CLs in cells prevents them from further going through biodegradation and excretion, resulting in unwanted cytotoxicity. Several different mechanisms, including oxidative stress, autophagy and certain physicochemical properties of nanoparticles (NPs), are reported to be associated with cellular toxicity (Wei et al. 2015; Xie and Wu 2016). Many experiments have found that CLs also have toxicity on cells or animals, which hinders the clinical application of CLs (Filion and Phillips 1997; Yang et al. 2016). Therefore, in-depth study of CLs is needed to explore the toxicity pathways and potential mechanisms underlying the vital role of CLs for the sake of widening the clinical application of CLs.

Metabolomics has emerged as a new discipline to study issues closely related to human health (Lindon et al. 2003). Meanwhile, the research on analysis of disease states as well as in basic research to study biological processes or in predictive toxicology has gradually attracted wide attention. Metabolomics is concerned with the analysis of all small endogenous metabolites in order to investigate the relationship between metabolites and toxic stimulating factors (Robertson 2005). It become a forceful tool for prospecting new high value compounds, taking insight into the potential toxicity mechanisms, and might have remarkable assistance for preventing the cellular toxicity in clinical (Tan et al. 2017). The liver is the main organ of metabolic clearance and has been recognized as the target site for drugs and nanoparticles (NPs). Evidence has shown that NPs preferentially deposit in the liver under systemic exposure, resulting in prolonged retention within the organ (B. Wang et al. 2013). Knowing that HepG2 is a hepatocyte carcinoma derived cell line and thought to be a more realistic and relevant model of hepatocyte behavior, we chose HepG2 to carry out our investigation (Johnston et al. 2010). Additionally, an UHPLC-Q-TOF/MS based metabolomics approach was carried out to analyze the potential mechanism underlying cellular toxicity of CLs exposure on HepG2 cells (G. Wang et al. 2016).

The aim of the present study was to evaluate the cellular toxicity of CLs on HepG2 cells, screen metabolites that undergo significant changes, and discuss the potential toxicity mechanism of CLs. Based on the screened metabolites, we used the free online MetaboAnalyst software to analyze the obtained statistical data and further create a heatmap via multivariate statistical analysis, cluster grams, and pathway analysis. The results demonstrate that metabolomics is a powerful method to gain insight into the toxicity mechanisms. To the best of our knowledge, the data shed lights on the mechanisms underlying the cellular toxicity of CLs and might have important implications for developing safe gene delivery systems.

\section{Materials and Methods}




\subsection{Chemicals and equipment}

Chemicals and equipment used in this study were optima grade methanol, formic acid, chloroform and acetonitrile of chromatographic grade (Merck); 1, 2-dioleoyl-3-trimethylammonium-propane (DOTAP) (890890P), cholesterol and DSPE-PEG 2000 (Avanti Polar Lipids, AL, USA); 3-Chloro-L-phenylalanine (Aladdin Reagent Co., Ltd); fetal bovine serum (FBS), penicillin, streptomycin phosphate-buffered saline (PBS) and DMEM (Invitrogen, CA, USA); deionized water purified by Millipore purification system (Millipore, MA, USA); and Cell Counting Kit (CCK-8) (Dojindo Laboratories, Kumamoto, Japan). All the other chemicals used in our research were of the highest analytic grade.

\subsection{Preparation and characterization of CLs}

CLs were synthesized by using the classical film dispersion method as described before (Yu et al. 2016; Kono et al. 2016). Briefly, DOTAP, cholesterol and DSPE-PEG 2000 at a molar ratio of 11:8:1 were dissolved in chloroform solution and mixed in a round-bottomed flask for about $1 \mathrm{~h}$. Then the organic solvents were removed from the lipid solution with a rotary evaporator. Subsequently, the lipid film was hydrated with $10 \mathrm{ml}$ PBS to create the multilamellar liposomes. Then the nano-scale unilamellar vesicles were prepared by forcing out the multilamellar liposomes using a liposomes extruder LF-1 (Avestin, Inc, Canada) at $56{ }^{\circ} \mathrm{C}$. Extrusion was accomplished in a step wise manner by performing membranes with progressively decreasing pore sizes (400, 200, $100 \mathrm{~nm}$, Whatman Nuclepore membrane, Fisher Scientific, MA, USA), with 10 cycles per pore size. CLs were then stored at $4{ }^{\circ} \mathrm{C}$ until use. The mean particle size, zeta potential and polydispersity index (PDI) of the CLs were measured using a Malvern Zetasizer ZS90 (Malvern Instruments, Ltd., UK).

Before measurement, newly prepared CLs were appropriately diluted $1: 10$ in $\mathrm{H}_{2} \mathrm{O}$ and all the operations were performed at room temperature after equilibration for $10 \mathrm{~min}$. Data were expressed as an average of three measurements.

\subsection{Cell culture}

The human hepatocellular carcinoma (HCC) cell line HepG2 was maintained in DMEM supplemented with $10 \%$ (v/v) FBS, penicillin (100 units $/ \mathrm{mL})$ and streptomycin $(100 \mu \mathrm{g} / \mathrm{mL})$. Cells were routinely cultured under the standard condition of $37{ }^{\circ} \mathrm{C}, 5 \% \mathrm{CO}_{2}$ and $95 \%$ humidity (Thermo Scientific, SERIESII WATER JACKET). 


\subsection{CCK-8 assay}

Cellular toxicity of CLs was assessed in HepG2 cells using the CCK-8 assay as described previously (Ko et al. 2015). During the experiment, HepG2 cells were seeded into a 96-well plate at a density of $1 \times 10^{4}$ cells per well and cultivated for $24 \mathrm{~h}$ to facilitate attachment to the surface, and then exposed to $100 \mu$ l culture medium with a concentration range of CLs for another $24 \mathrm{~h}$; untreated cells were used as control groups and each group was further divided into 4 parallel wells. After treatment with CCK-8 solution for another $4 \mathrm{~h}$ at $37^{\circ} \mathrm{C}$, the absorbance was measured at $450 \mathrm{~nm}$ using an absorbance microplate reader (Thermo Fisher Scientific Inc., Multiskan, MK3). Subsequently, cell viability was compared with that of the control using the following equation: $A_{a} / A_{b} \times 100$, where $A_{a}$ and $A_{b}$ are the absorbance of experimental samples and controls, respectively. Half-maximum inhibitory concentration $\left(\mathrm{IC}_{50}\right)$ values of $\mathrm{CLs}$ were calculated by the Graphpad software.

\subsection{Sample collection and preparation}

Cells were cultured overnight in a $100-\mathrm{mm}$ dish at a density of $1 \times 10^{6}$ cells per dish, followed by incubation with a concentration of $\mathrm{IC}_{50}$ of $\mathrm{CLs}$ for $24 \mathrm{~h}$. In each experiment, untreated cells were used as control and six biological replicates were performed. Next, cell lysates were obtained by adding $1 \mathrm{ml}$ of cold methanol to each dish and mechanically harvested with a sterile plastic disposable cell scraper. Each dish was washed with an additional $500 \mu$ l cold methanol that was collected into the respective Eppendorf ${ }^{\oplus}$ tube. Recovered cell lysate was vortexed for 1 min and further centrifuged at $13,000 \times \mathrm{g}$ for $15 \mathrm{~min}$ at $4{ }^{\circ} \mathrm{C}$. The supernatant was collected and stored in a new $1.5 \mathrm{ml}$ Eppendorf ${ }^{\oplus}$ tube at $-80{ }^{\circ} \mathrm{C}$. The methanol solution was evaporated to dryness and the sample was re-suspended in $250 \mu \mathrm{l}$ pre-cooling reagent (methanol: chloroform, 9:1) containing $1 \mu \mathrm{g} / \mathrm{ml}$ 3-chloro-L-phenylalanine as the internal standard. After being vortexed for $2 \mathrm{~min}$, the sample was centrifuged at $13,000 \times \mathrm{g}, 4{ }^{\circ} \mathrm{C}$ for $15 \mathrm{~min}$, and then added with $200 \mu \mathrm{l}$ supernatant in the sample vial for LC-MS analysis. A QC sample was accomplished by mixing aliquots from each supernatant (10 $\mu$ l per sample).

\subsection{Chromatography and mass spectrometry conditions}

An Agilent Infinity 1290 series instrument (Agilent, CA, USA) equipped with an auto sampler delivery system was used for UHPLC analysis. The chromatographic separation was performed on a HSS $\mathrm{T}_{3}$ column (100 mm $\times 2.1 \mathrm{~mm}, 2.5 \mu \mathrm{m}$, Waters Corporation, USA). The mobile phase consisted of $0.05 \%$ formic acid (solvent $A$ ) and acetonitrile with $0.05 \%$ formic acid (solvent $B$ ). The column temperature was maintained at $25{ }^{\circ} \mathrm{C}$ and the injection volume was $3 \mu$. Post time was 
set at $5 \mathrm{~min}$ and the flow-rate was $0.40 \mathrm{ml} / \mathrm{min}$. The optimized elution condition was applied as follows: 0-2 $\min , 5 \% \mathrm{~B} ; 2-17 \mathrm{~min}, 5-95 \% \mathrm{~B} ; 17-19 \mathrm{~min}, 95 \% \mathrm{~B}$.

The UHPLC system was connected to an Agilent 6538 accurate mass quadrupole time-of-flight mass spectrometer (Agilent Technologies, USA) with an electrospray ionization source operating in both positive and negative modes. The ESI source conditions were optimized as follows: capillary voltage, $4 \mathrm{kV}$ in positive mode and $3.5 \mathrm{kV}$ in negative mode; drying gas flow, $11 \mathrm{~L} / \mathrm{min}$; gas temperature, $350{ }^{\circ} \mathrm{C}$; Nebulizer pressure, 45 psig; fragmentor voltage, $120 \mathrm{~V}$; skimmer voltage, $60 \mathrm{~V}$; collision energy, 10, 20, 30, and 40 eV. Accurate LC-MS mass spectra were recorded across an $\mathrm{m} / \mathrm{z}$ range of 100 to $1200 \mathrm{Da}$. The MS/MS method was applied to further confirm the biomarkers.

\subsection{Data processing and statistical analysis}

UHPLC-Q-TOF/MS spectra of all determined samples were recorded and converted into a common data file format (mzdata); subsequently, the collected data were extracted by molecular feature extraction with the retention time (Rt), $\mathrm{m} / \mathrm{z}$ value, and the corresponding intensities for all detected peaks in the data set. The $80 \%$ rule was used to select the ions, and then normalization and auto-scaling of the ion peaks were performed. To compare the differences of the two groups and find out the significant metabolites, a Student's t-test of all the screened peaks was carried out using IBM SPSS Statistic Version 17.0 (IBM, New York, USA). The data set containing all the peak area corresponding to the concentration of a certain metabolite was exported to the SIMCA-P software (version 11, Sweden) for PCA and PLS-DA analysis. PLS-DA produced the key parameters: $R^{2} X$ (the cumulative model variation in $X$ ), $R^{2} Y$ (the cumulative model variation in $\mathrm{Y}$ ) and $\mathrm{Q}^{2}$ (the cumulative predicted variation). As these parameters approached 1.0, a model with predictive reliability appeared.

All data showed in the figures are expressed as the means \pm standard deviation (SD) and were assessed using the ANOVA or the Student's t-test. Differences between the two groups were considered statistically significant using the least significant differences at the values of $p<$ 0.05 .

\section{Results}

\subsection{Characterization of CLs}

CLs were characterized using a Zetasizer ZS90 to determine their diameter and size distribution. All samples were diluted 10 -fold with ultrapure water. PDI was a measure of the 
uniformity of particle sizes present in the suspension, ranging from 0 (mono dispersed) to 1 (very broad distribution), knowing that its value can reflect the homogenous size distribution of CLs. The physical parameters measured by the Malvern particle size analyzer are shown in Table 1. The size and zeta potential distributions are shown in Fig S1. Data are expressed as the mean \pm standard deviation (SD). All measurements were carried out in triplicate at $25{ }^{\circ} \mathrm{C}$ after $3 \mathrm{~min}$ equilibration. It was found that CLs were well dispersed and uniform in shape and size.

\subsection{Cellular toxicity of CLs}

The potential effect of $\mathrm{CLs}$ on toxicity of HepG2 cells was investigated. The results demonstrated that the number of HepG2 cells was decreased markedly in a concentration-dependent manner after exposure to CLs, with an $I_{50}$ value of $119.9 \mu \mathrm{g} / \mathrm{ml}$ (Fig 1). In addition, no obvious cellular toxicity was observed when the dose of CLs was lower than 50 $\mu \mathrm{g} / \mathrm{ml}$. But when the dose of CLs was increased to the highest level for $24 \mathrm{~h}$, the inhibitory effect increased by approximately $96 \%$, suggesting that CLs reduced the viability of HepG2 cells remarkably. To identify the alternated level of metabolites more exactly and accurately, an $\mathrm{IC}_{50}$ value of $119.9 \mu \mathrm{g} / \mathrm{ml}$ was chosen for subsequent experiments.

\subsection{Method validation}

The UHPLC-Q-TOF/MS system was used to detect the cell samples. The representative total ion current (TICS) chromatograms of both groups gained from positive and negative mode are shown in Fig S2.

A QC sample was applied to validate the system performance and obtain complementary product ion information. At the same time, five selected ions were calculated for the relative standard deviation (RSD) of the retention time and the peak area for validation. The RSD of retention time was less than $1 \%$ and the peak area was less than $5 \%$, demonstrating that the method was precise, stable and reliable for subsequent analyses.

\subsection{Metabolomics analysis}

To gain the whole metabolic information and investigate the alteration, the pattern recognition methods such as PCA and PLS-DA were performed on the resulting complex multivariate data set. Major metabolites were identified by high-resolution mass spectrometry and MS/MS experiments. The typical score plots between the control and CLs groups are shown in Fig 2. PCA was looking forward to searching the intrinsic variation in the data set, and the results (Fig $2 \mathrm{~A}$ and $\mathrm{B}$ ) indicate that the clusters of the extracts from CLs group were clearly 
separated from those of the relevant control, suggesting a significant alteration in the metabolic profile induced by CLs.

Knowing that PLS-DA is a supervised method mainly for discovering variation, it was used to identify metabolic differences between the two groups in this study. The pair-wise PLS-DA score plots in positive and negative ion modes are shown in Fig 2 C, D and Fig S3, showing a significant difference between CLs and corresponding control groups. In the PLS-DA model, S-plots are usually used to identify the features contributing to group discrimination. Each spot represents an endogenous substance, and the spots located at the ends of the plot will contribute more to the differentiation between groups (Fig $2 \mathrm{E}$ and F).

\subsection{Identification of differential metabolites}

UHPLC-MS and metabolomics data analyses were used to assess the difference in the metabolic profile within cells exposed to CLs vs. the untreated control. The potential metabolites were picked out according to Variable Importance in the Project at the values of VIP >1.0, and the S-plot. Some of these metabolites and the interpretation of significant ion peaks were preceded by searching metabolic databases including HMDB, KEGG, and METLIN. In addition, these candidate metabolites from both groups were verified by comparison of the retention time and fragmentation pattern with authentic standards according to the MS/MS experiments. Subsequently, the literature and KEGG database (http://www.genome.jp/kegg/) were selected to interpret the pathways of the metabolites. Altogether 42 differential metabolites, including 23 in positive and 19 in negative modes, were identified, and the details are shown in Table 2.

\subsection{Function analysis and metabolic pathway}

To visualize the level of metabolite change, a heatmap was built according to the peak area transformed data of metabolites. The heatmap based on the 42 metabolites showed significant differences between CLs and control groups (Fig S4), based on which a metabolic pathway analysis was further performed to evaluate their associated pathways. The result showed that the changed metabolites identified were primarily involved in amino acid metabolism, energy metabolism, lipid and oxidative stress. Fig 4 shows an overview of the pathway analysis, with the $\mathrm{x}$-axis (the pathway impact value calculated from pathway topological analysis) and the $y$-axis (corresponding to the $-\log (\mathrm{p})$ value obtained from pathway enrichment analysis), with the most impacted pathways colored. Consequently, nine most significantly different pathways were considered closely related to the potential cellular toxicity induced by CLs. These pathways involved arachidonic acid metabolism, D-glutamine and D-glutamate metabolism, sphingolipids 
metabolism, pantothenate and CoA biosynthesis, GSH metabolism, TCA cycle, phenylalanine metabolism, glycerophospholipid metabolism, and purine metabolism.

Based on the KEGG pathway database, we established the metabolic network (Fig 4), which clearly showed that CLs were related to the above-mentioned metabolites.

\section{Discussion}

To further explore cellular toxicity of CLs on HepG2 cells, we investigated the metabolic alterations in HepG2 cell extracts after 24-h continuous incubation with CLs by employing the UHPLC-Q-TOF/MS-based metabolomics approach. Subsequent analysis of the metabolite profiles of the samples from HepG2 cells provided a fingerprint of metabolic changes and highlighted the potential of metabolomics analysis in the evaluation of toxicity. About 42 metabolic biomarkers were highly possible to be associated with CLs-exposure, because they showed better performance in terms of both specificity and sensitivity. These differential metabolites mostly included amino acids, lipids, and fatty acids.

In our study, nine unique metabolic pathways were identified from CLs and control groups (Fig 3). The altered metabolites related to CLs-exposure were mainly involved in amino acid metabolism, energy metabolism, oxidative stress metabolism and lipid metabolism (Fig 4).

\subsection{Amino acid metabolism}

One recent study (Wei et al. 2015) reported that CLs could impair the activity of $\mathrm{Na}^{+} / \mathrm{K}^{+}$-ATPase in cells, leading to cell anoxia and acute cell necrosis. Cell necrosis is known to affect endogenous metabolites. Amino acids are the most fundamental substances in the organism and the most important substrate materials for synthetic proteins closely related to the life activities of cells.

Phenylalanine belonging to aromatic amino acid is a kind of essential amino acid and the precursor for tyrosine. On the one hand, phenylalanine is used to synthesize proteins in diverse cells; most phenylalanine in vivo is catalyzed by phenylalanine hydroxylase to generate tyrosine. In addition, tyrosine is further synthesized into essential hormones to participate in sugar and lipid metabolisms. On the other hand, only a small proportion of phenylalanine is metabolized into phenylpyruvic acid (Du et al. 2016). Glutamic acids are substances required for the production of glutathione (GSH), the most abundant natural antioxidant in the body. It was found in our study that the content of GSH was increased, probably due to CLs-induced oxidative stress, which in turn increased glutamate and glycine to contribute to GSH production. In addition, a 
panel of amino acids (phenylalanine, tyrosine, glutamic acid and citrulline) underwent significant changes in HepG2 cells compared with those in control group. These changes may be partly attributed to the disordered amino acid metabolism.

\subsection{Energy metabolism}

Energy metabolism is the key element in the regulation of life and death. Multiple metabolites such as creatine, oxalacetic acid, ATP and NADH are known to pay important roles in the cycle of energy metabolism.

* Creatine is part of the cellular energy shuttle synthesized mainly in the liver by making use of arginine, glycine, and methionine. It was found in our study that creatine was increased significantly in CLs group as compared with that in control group, indicating a perturbation of energy metabolism in HepG2 cells exposed to CLs. This finding, together with previous findings, may indirectly suggest that disturbed energy metabolism is involved in CLs exposure. Oxalacetic acid and thiamin diphosphate are important intermediates in TCA cycle. TCA cycle in association with oxidative phosphorylation is the major pathway in cellular energy production. On the other hand, phosphocholine is generated in a reaction catalyzed by choline kinase that converts ATP and choline into phosphocholine and ADP. Thus, change in phosphocholine implies that there is some disturbance in energy metabolism induced by CLs in HepG2 cells. At the same time, choline is a major constituent part of the cell membrane and plays an essential role in the integrity of cell membranes and lipid metabolism. The elevated concentrations of choline in the extracts denote the disruption of membrane fluidity caused by CLs. The production of energy partly depends on the oxygen-dependent electron transfer chain in cells; once the process is disturbed, the concentration of $\mathrm{NADH}, \mathrm{FADH}_{2}$ and ubiquinone- 4 is altered in cells. In our study, AMP and ADP levels in CLs group were markedly decreased as compared with those in control group, suggesting that disturbed energy metabolism may be involved in CLs exposure. Pantothenic acid is the precursor of coenzyme $A(C o A)$, and also plays a significant role in lipid metabolism or as a prosthetic group in TCA cycle (Li et al. 2010; Monteiro et al. 2015). The increased level of pantothenic acid suggests that CLs exposure might induce the disturbance of coenzyme $A$ and TCA cycle.

\subsection{Oxidative stress}

GSH is the most abundant amino acid and plays an important role in anti-oxidation. It can protect some thiol containing proteins or enzymes from being damaged by oxidants, especially peroxide (Hussain et al. 2005). In the current investigation, we found significant alterations in the 
levels of GSH and GSSG in HepG2 cells, suggesting that CLs exposure could induce free radicals, which is consistent with the previous finding that liposome-exposure could promote the production of produced reactive oxygen species (ROS) (Jia et al. 2009; Gioria et al. 2016). ROS is a key signal to transmit environmental stimuli in cells in response to stress. The surface of the NPs could cause oxidative stress, thus increasing intracellular calcium and gene activation, or intracellular distribution of NPs may affect mitochondria thereby generating oxidative stress (F. Wang et al. 2009).

Leukotriene (LT) and prostaglandin (PG) are minor metabolites of arachidonic acid under the action of inflammatory stimulation. They are also vital inflammatory mediators. It was found in our study that LTE4 and PGH2 levels were upregulated in CLs group, suggesting that CLs exposure may induce inflammation in HepG2 cells. Our experimental data demonstrate that oxidative stress caused by NPs could induce inflammation, resulting in DNA damage, which is consistent with the result of another study (Ma et al. 2011; Trinei et al. 2002). Adenine and dUMP are nucleotides, and the substrates of DNA or RNA as well (Davies et al. 2012; Rai et al. 2009). In the CLs-exposed modes, we observed a significant increase in the content of the above nucleotides, indicating that CLs exposure triggered the inflammatory process and disturbed nucleotides.

\subsection{Lipid metabolism}

Numerous studies have demonstrated that disturbance of lipid metabolism plays a pivotal role in the progression of toxicity of NPs exposure (Rajiv et al. 2016;Tian et al. 2016;Arisaka et al. 2011). An earlier transcriptomic study from our group found significant perturbations in mRNA associated with lipid metabolism in HepG2 cell extracts after CLs exposure. Both PC and GPC are derivatives of choline and two main storage forms of choline in the cytoplasm. Choline-like metabolites are involved in several important pathways, playing signaling and structural roles in cell membranes and immune response. It was found in this study that the content of these two metabolites was both significantly up-regulated in CLs group, indicating that the increase in these metabolites may help remove damaged cells after CLs exposure. Three unsaturated fatty acids (arachidonic acid, 17-hydroxylinolenic acid and docosahexaenoic acid) were also increased markedly in CLs group. Arachidonic acid, which is known to possess inflammatory response-mediating properties, is a polyunsaturated essential fatty acid and a vital component of phosphatides. However, arachidonic acid has cytotoxicity and may work as a physiological mediator of cell death. 17-hydroxylinolenic acid and docosahexaenoic acid are two important polyunsaturated fatty acids that play a vital role in many metabolic and cell signaling processes. We also observed a significant increase in some metabolites including ceramide and cholesterol 
in CLs group vs. control group. Therefore, the significant perturbations in these lipid metabolites may be closely related to lipid metabolic dysfunction of CLs-induced cell death.

The process of fatty acid degradation, also known as beta-oxidation, converts an aliphatic compound into a set of activated acetyl units (acetyl CoA) that can be processed by TCA cycle. Carnitine cycle is the first step for fatty acid oxidation, in which fatty acyl CoA enters the mitochondria as fatty acyl carnitines via carnitine transport. Numerous disorders involving energy production and excretion of unusual acylcarnitines have been described. In this study, acetylcarnitine and palmitoylcarnitine were decreased in CLs group, indicating that the abnormality of fatty acid metabolism might be associated with the toxicity of CLs. Bile acids are physiological detergents that facilitate the excretion, absorption and transport of fats and sterols. The increased concentration of cholic acid in CLs group was observed, suggesting that CLs could disturb bile biosynthesis and cholesterol metabolism.

\subsection{Other metabolisms}

Sarcosine, SAM and N5-Formyl-THF are sources of methyl groups. The methylation process helps cells respond to stress, detoxify xenobiotics and generate methylated compounds. The lack of methyl will affect the methylation of DNA and RNA, thus interfering with nucleic acid synthesis and affecting the normal metabolism of overall circulation. The change of methyl, as reflected in the concentrations of these metabolites with methyl sources such as choline, sarcosine, SAM, and N5-Formyl-THF, suggesting that methylation plays a vital role in detoxification of CLs exposure.

\section{Conclusions}

Recent advances in metabolomics technologies have made it possible to analyze a wide range of bimolecules qualitatively and quantitatively, and determine their relative abundance in different biological conditions. In the present research, UHPLC-Q-TOF/MS-based metabolomics method coupled with multivariate data analysis was employed to evaluate the toxicological effect of CLs in vitro. A total of 42 differentially expressed metabolites induced by CLs were screened between CLs and control groups. These metabolites belonged to the classification of amino acids, fatty acids and lipids and were mainly associated with the distribution of some metabolic pathways including amino acid metabolism, energy metabolism, and the metabolism of phospholipid and fatty acid. Our results highlight that CLs may exert their toxicity via different pathways, although this postulation needs to be verified by more studies.

This article is protected by copyright. All rights reserved. 
Our findings demonstrate that the metabolomics approach can be employed as a tool to understand the toxicity mechanism of CLs. In addition, these results may serve as useful clues for further investigations needed to better understand the toxicity mechanisms of CLs. Our ongoing study will construct a molecular network to further explore the mechanism underlying cytotoxicity of CLs by transcriptomics and proteomics analysis.

\section{Acknowledgments}

This study was supported by the funding of the Science and Technology Commission of Shanghai Municipality (15540723500). We would also like to express the sincere gratitude to Hongli Du for her help in this manuscript.

\section{Conflict of interest}

The authors declare that they have no conflict of interests.

\section{References}

Andresen, T. L., Jensen, S. S., \& Jorgensen, K. (2005). Advanced strategies in liposomal cancer therapy: problems and prospects of active and tumor specific drug release. Prog Lipid Res, 44(1), 68-97, doi:10.1016/j.plipres.2004.12.001.

Arisaka, M., Takano, K., Negishi, Y., Arima, H., \& Aramaki, Y. (2011). Involvement of lipid rafts in macrophage apoptosis induced by cationic liposomes. Arch Biochem Biophys, 508(1), 72-77, doi:10.1016/j.abb.2011.02.003.

Cortesi, R., Damiani, C., Ravani, L., Marvelli, L., Esposito, E., Drechsler, M., et al. (2015). Lipid-based nanoparticles containing cationic derivatives of PTA (1,3,5-triaza-7-phosphaadamantane) as innovative vehicle for Pt complexes: Production, characterization and in vitro studies. Int J Pharm, 492(1-2), 291-300, doi:10.1016/j.ijpharm.2015.07.021.

Davies, O., Mendes, P., Smallbone, K., \& Malys, N. (2012). Characterisation of multiple substrate-specific (d)ITP/(d)XTPase and modelling of deaminated purine nucleotide metabolism. BMB Rep, 45(4), 259-264.

Du, H., Wang, K., Su, L., Zhao, H., Gao, S., Lin, Q., et al. (2016). Metabonomic identification of the effects of the Zhimu-Baihe saponins on a chronic unpredictable mild stress-induced rat model of depression. J Pharm Biomed Anal, 128, 469-479, doi:10.1016/j.jpba.2016.06.019. 
Filion, M. C., \& Phillips, N. C. (1997). Toxicity and immunomodulatory activity of liposomal vectors formulated with cationic lipids toward immune effector cells. Biochim Biophys Acta, $1329(2), 345-356$.

Gioria, S., Lobo Vicente, J., Barboro, P., La Spina, R., Tomasi, G., Urban, P., et al. (2016). A combined proteomics and metabolomics approach to assess the effects of gold nanoparticles in vitro. Nanotoxicology, 10(6), 736-748, doi:10.3109/17435390.2015.1121412.

Gujrati, M., Malamas, A., Shin, T., Jin, E., Sun, Y., \& Lu, Z. R. (2014). Multifunctional cationic lipid-based nanoparticles facilitate endosomal escape and reduction-triggered cytosolic siRNA release. Mol Pharm, 11(8), 2734-2744, doi:10.1021/mp400787s.

Jia, H. Y., Liu, Y., Zhang, X. J., Han, L., Du, L. B., Tian, Q., et al. (2009). Potential oxidative stress of gold nanoparticles by induced-NO releasing in serum. J Am Chem Soc, 131(1), 40-41, doi:10.1021/ja808033w.

Johnston, H. J., Semmler-Behnke, M., Brown, D. M., Kreyling, W., Tran, L., \& Stone, V. (2010). Evaluating the uptake and intracellular fate of polystyrene nanoparticles by primary and hepatocyte cell lines in vitro. Toxicol Appl Pharmacol, 242(1), 66-78, doi:10.1016/j.taap.2009.09.015.

Kagan, V. E., Bayir, H., \& Shvedova, A. A. (2005). Nanomedicine and nanotoxicology: two sides of the same coin. Nanomedicine, 1(4), 313-316, doi:10.1016/j.nano.2005.10.003.

Knudsen, K. B., Northeved, H., Kumar, P. E., Permin, A., Gjetting, T., Andresen, T. L., et al. (2015). In vivo toxicity of cationic micelles and liposomes. Nanomedicine, 11(2), 467-477, doi:10.1016/j.nano.2014.08.004

Ko, W. K., Heo, D. N., Moon, H. J., Lee, S. J., Bae, M. S., Lee, J. B., et al. (2015). The effect of gold nanoparticle size on osteogenic differentiation of adipose-derived stem cells. J Colloid Interface Sci, 438, 68-76, doi:10.1016/j.jcis.2014.08.058.

Kono, Y., Iwasaki, A., Matsuoka, K., \& Fujita, T. (2016). Effect of Mechanical Agitation on Cationic Liposome Transport across an Unstirred Water Layer in Caco-2 Cells. Biol Pharm Bull, 39(8), 1293-1299, doi:10.1248/bpb.b16-00050.

Li, L. O., Hu, Y. F., Wang, L., Mitchell, M., Berger, A., \& Coleman, R. A. (2010). Early hepatic insulin resistance in mice: a metabolomics analysis. Mol Endocrinol, 24(3), 657-666, 
doi:10.1210/me.2009-0152.

Lindon, J. C., Nicholson, J. K., Holmes, E., Antti, H., Bollard, M. E., Keun, H., et al. (2003). Contemporary issues in toxicology the role of metabonomics in toxicology and its evaluation by the COMET project. Toxicol Appl Pharmacol, 187(3), 137-146.

Ma, Y., Zhuang, Y., Xie, X., Wang, C., Wang, F., Zhou, D., et al. (2011). The role of surface charge density in cationic liposome-promoted dendritic cell maturation and vaccine-induced immune responses. Nanoscale, 3(5), 2307-2314, doi:10.1039/c1nr10166h.

Monteiro, D. C., Patel, V., Bartlett, C. P., Nozaki, S., Grant, T. D., Gowdy, J. A., et al. (2015). The structure of the PanD/PanZ protein complex reveals negative feedback regulation of pantothenate biosynthesis by coenzyme A. Chem Biol, 22(4), 492-503, doi:10.1016/j.chembiol.2015.03.017.

Rai, P., Onder, T. T., Young, J. J., McFaline, J. L., Pang, B., Dedon, P. C., et al. (2009). Continuous elimination of oxidized nucleotides is necessary to prevent rapid onset of cellular senescence. Proc Natl Acad Sci U S A, 106(1), 169-174, doi:10.1073/pnas.0809834106.

Rajiv, S., Jerobin, J., Saranya, V., Nainawat, M., Sharma, A., Makwana, P., et al. (2016). Comparative cytotoxicity and genotoxicity of cobalt (II, III) oxide, iron (III) oxide, silicon dioxide, and aluminum oxide nanoparticles on human lymphocytes in vitro. Hum Exp Toxicol, 35(2), 170-183, doi:10.1177/0960327115579208.

Robertson, D. G. (2005). Metabonomics in toxicology: a review. Toxicol Sci, 85(2), 809-822, doi:10.1093/toxsci/kfi102.

Romoren, K., Thu, B. J., Bols, N. C., \& Evensen, O. (2004). Transfection efficiency and cytotoxicity of cationic liposomes in salmonid cell lines of hepatocyte and macrophage origin. Biochim Biophys Acta, 1663(1-2), 127-134, doi:10.1016/j.bbamem.2004.02.007.

Tan, J., Wang, Y., Wang, S., Zhang, N., Wu, S., Yuan, Z., et al. (2017). Untargeted metabolomics analysis of adipogenic transformation in OP9-DL1 cells using liquid chromatography-mass spectrometry: Implications for thymic adipogenesis. Cell Biol Int, doi:10.1002/cbin.10740.

Tian, J. H., Hu, J. S., Li, F. C., Ni, M., Li, Y. Y., Wang, B. B., et al. (2016). Effects of TiO2 nanoparticles on nutrition metabolism in silkworm fat body. Biol Open, 5(6), 764-769, doi:10.1242/bio.015610.

This article is protected by copyright. All rights reserved. 
Trinei, M., Giorgio, M., Cicalese, A., Barozzi, S., Ventura, A., Migliaccio, E., et al. (2002). A p53-p66Shc signalling pathway controls intracellular redox status, levels of oxidation-damaged DNA and oxidative stress-induced apoptosis. Oncogene, 21(24), 3872-3878, doi:10.1038/sj.onc.1205513.

Wang, B., He, X., Zhang, Z., Zhao, Y., \& Feng, W. (2013). Metabolism of nanomaterials in vivo: blood circulation and organ clearance. Acc Chem Res, 46(3), 761-769, doi:10.1021/ar2003336.

Wang, F., Gao, F., Lan, M., Yuan, H., Huang, Y., \& Liu, J. (2009). Oxidative stress contributes to silica nanoparticle-induced cytotoxicity in human embryonic kidney cells. Toxicol In Vitro, 23(5), 808-815, doi:10.1016/j.tiv.2009.04.009.

Wang, G., Fu, H., Ye, W., Zheng, X., Xiao, J., Kang, D., et al. (2016). Comprehensive characterization of the in vitro and in vivo metabolites of ziyuglycoside I in rat microsome, intestinal flora, excretion specimen and fresh tissues based on LC-Q-TOF/MS. J Pharm Biomed Anal, 128, 191-200, doi:10.1016/j.jpba.2016.05.032.

Wei, X., Shao, B., He, Z., Ye, T., Luo, M., Sang, Y., et al. (2015). Cationic nanocarriers induce cell necrosis through impairment of $\mathrm{Na}^{(+)} / \mathrm{K}^{(+)}$-ATPase and cause subsequent inflammatory response. Cell Res, 25(2), 237-253, doi:10.1038/cr.2015.9.

Xie, H., \& Wu, J. (2016). Silica nanoparticles induce alpha-synuclein induction and aggregation in PC12-cells. Chem Biol Interact, 258, 197-204, doi:10.1016/j.cbi.2016.09.006.

Yang, K., Lu, Y., Xie, F., Zou, H., Fan, X., Li, B., et al. (2016). Cationic liposomes induce cell necrosis through lysosomal dysfunction and late-stage autophagic flux inhibition. Nanomedicine (Lond), 11(23), 3117-3137, doi:10.2217/nnm-2016-0289.

Yu, J., Yang, H., Li, K., Lei, J., Zhou, L., \& Huang, C. (2016). A novel application of nanohydroxyapatite/mesoporous silica biocomposite on treating dentin hypersensitivity: An in vitro study. J Dent, 50, 21-29, doi:10.1016/j.jdent.2016.04.005.

\section{Figure caption}

This article is protected by copyright. All rights reserved. 
Table 1. The physical characterizations of CLs

\begin{tabular}{cccc}
\hline Polymer & Size $(\mathrm{nm})$ & PDI & ZP $(\mathrm{mV})$ \\
\hline $\mathrm{CLS}$ & $152.2 \pm 4.04$ & $0.117 \pm 0.013$ & $8.38 \pm 4.96$ \\
\hline
\end{tabular}

PDI=polydispersity index, $Z \mathrm{P}=$ zeta potential, $\mathrm{n}=3$

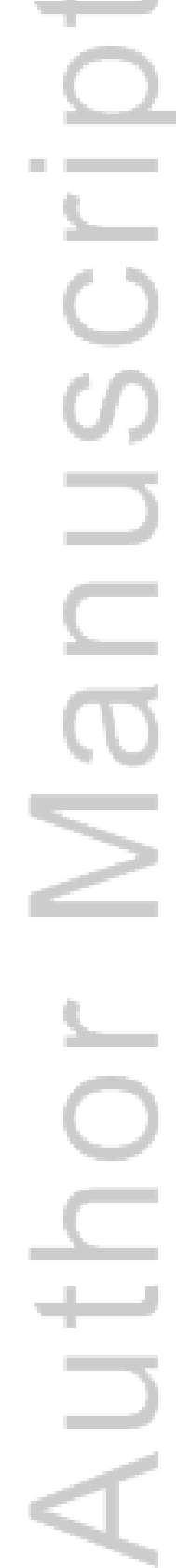

This article is protected by copyright. All rights reserved. 
Table 2. Significant metabolomics profiles measured by UHPLC-Q-TOF/MS

\begin{tabular}{|c|c|c|c|c|c|c|c|c|c|}
\hline No. & $\mathrm{m} / \mathrm{z}$ & RT & VIP & Ion & Formula & Metabolites & Pathways & \multicolumn{2}{|c|}{$\mathrm{FC}(\mathrm{CLs} / \mathrm{C})$} \\
\hline 1 & 175.1857 & 0.9805 & 1.791 & {$[\mathrm{M}-\mathrm{H}]^{-}$} & $\mathrm{C}_{6} \mathrm{H}_{13} \mathrm{~N}_{3} \mathrm{O}_{3}$ & Citrulline & Amino acids metabolism & 1.373 & 个\#\# \\
\hline 2 & 307.323 & 0.9927 & 2.731 & {$[\mathrm{M}+\mathrm{H}]^{+}$} & $\mathrm{C}_{10} \mathrm{H}_{17} \mathrm{~N}_{3} \mathrm{O}_{6} \mathrm{~S}$ & GSH & Glutathione metabolism & 3.461 & 个\# \\
\hline 3 & 308.1819 & 0.9977 & 1.043 & {$[\mathrm{M}+\mathrm{H}]^{+}$} & $\mathrm{C}_{9} \mathrm{H}_{13} \mathrm{~N}_{2} \mathrm{O}_{8} \mathrm{P}$ & dUMP & Energy metabolism & 0.514 & 个\# \\
\hline 4 & 612.631 & 1.0039 & 2.577 & {$[\mathrm{M}-\mathrm{H}]^{-}$} & $\mathrm{C}_{20} \mathrm{H}_{32} \mathrm{~N}_{6} \mathrm{O}_{12} \mathrm{~S}_{2}$ & Oxidized glutathione & Glutathione metabolism & 3.155 & 个\# \\
\hline 5 & 35.1267 & 1.1637 & 1.167 & {$[\mathrm{M}+\mathrm{H}]^{+}$} & $\mathrm{C}_{5} \mathrm{H}_{5} \mathrm{~N}_{5}$ & Adenine & Purine metabolism & 0.534 & 个\#\# \\
\hline 6 & 131.1332 & 1.2292 & 5.225 & {$[\mathrm{M}+\mathrm{H}]^{+}$} & $\mathrm{C}_{4} \mathrm{H}_{9} \mathrm{~N}_{3} \mathrm{O}_{2}$ & Creatine & Energy metabolism & 11.53 & 个\# \\
\hline 7 & 132.0716 & 1.2304 & 1.446 & {$[\mathrm{M}+\mathrm{H}]^{+}$} & $\mathrm{C}_{4} \mathrm{H}_{4} \mathrm{O}_{5}$ & Oxalacetic acid & Energy metabolism & 0.913 & 个\# \\
\hline 8 & 164.158 & 1.7637 & 1.053 & {$[\mathrm{M}+\mathrm{H}]^{+}$} & $\mathrm{C}_{9} \mathrm{H}_{8} \mathrm{O}_{3}$ & Phenylpyruvic acid & Amino acids metabolism & 0.446 & 个\#\# \\
\hline
\end{tabular}

This article is protected by copyright. All rights reserved. 


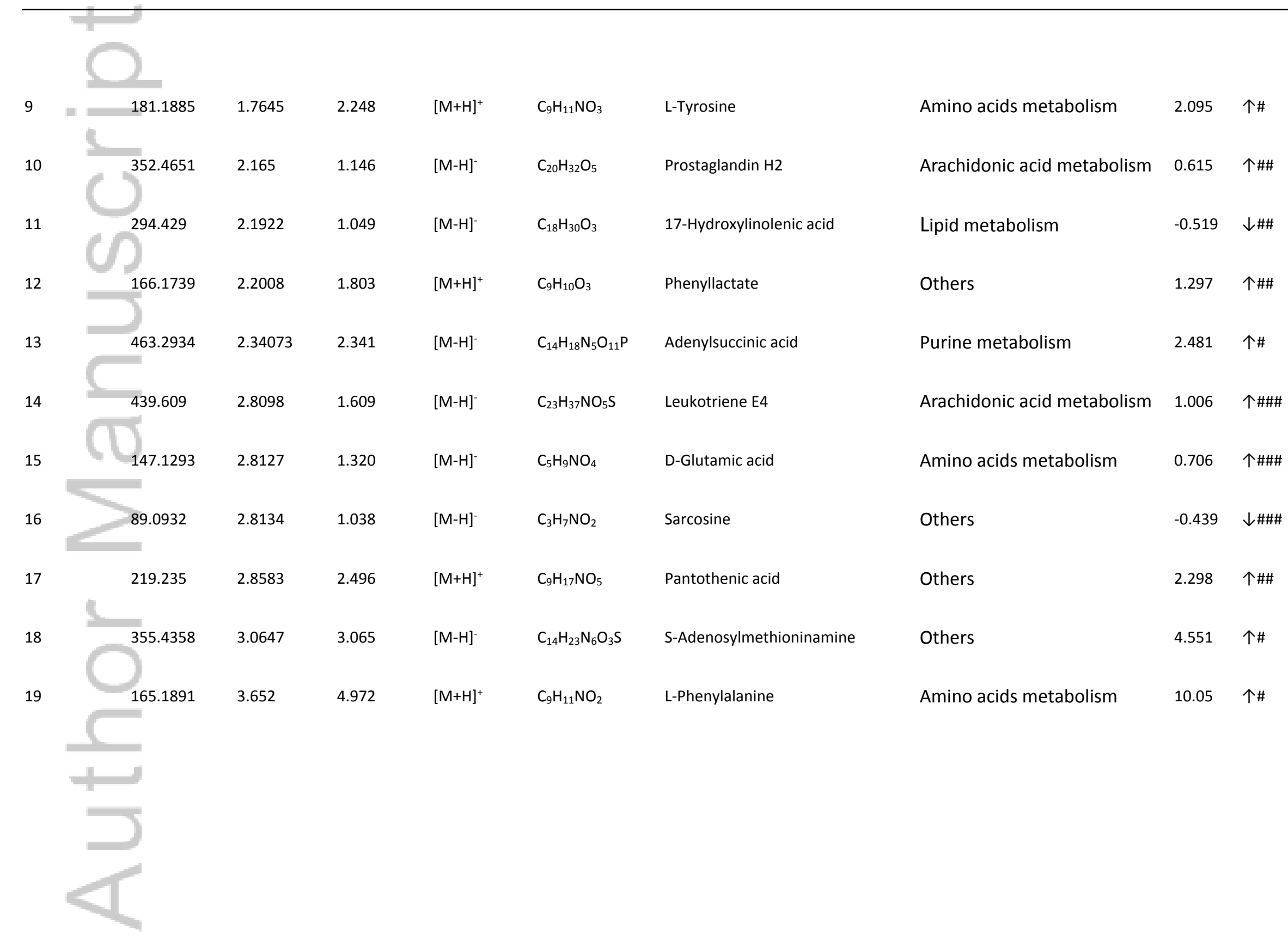

This article is protected by copyright. All rights reserved. 


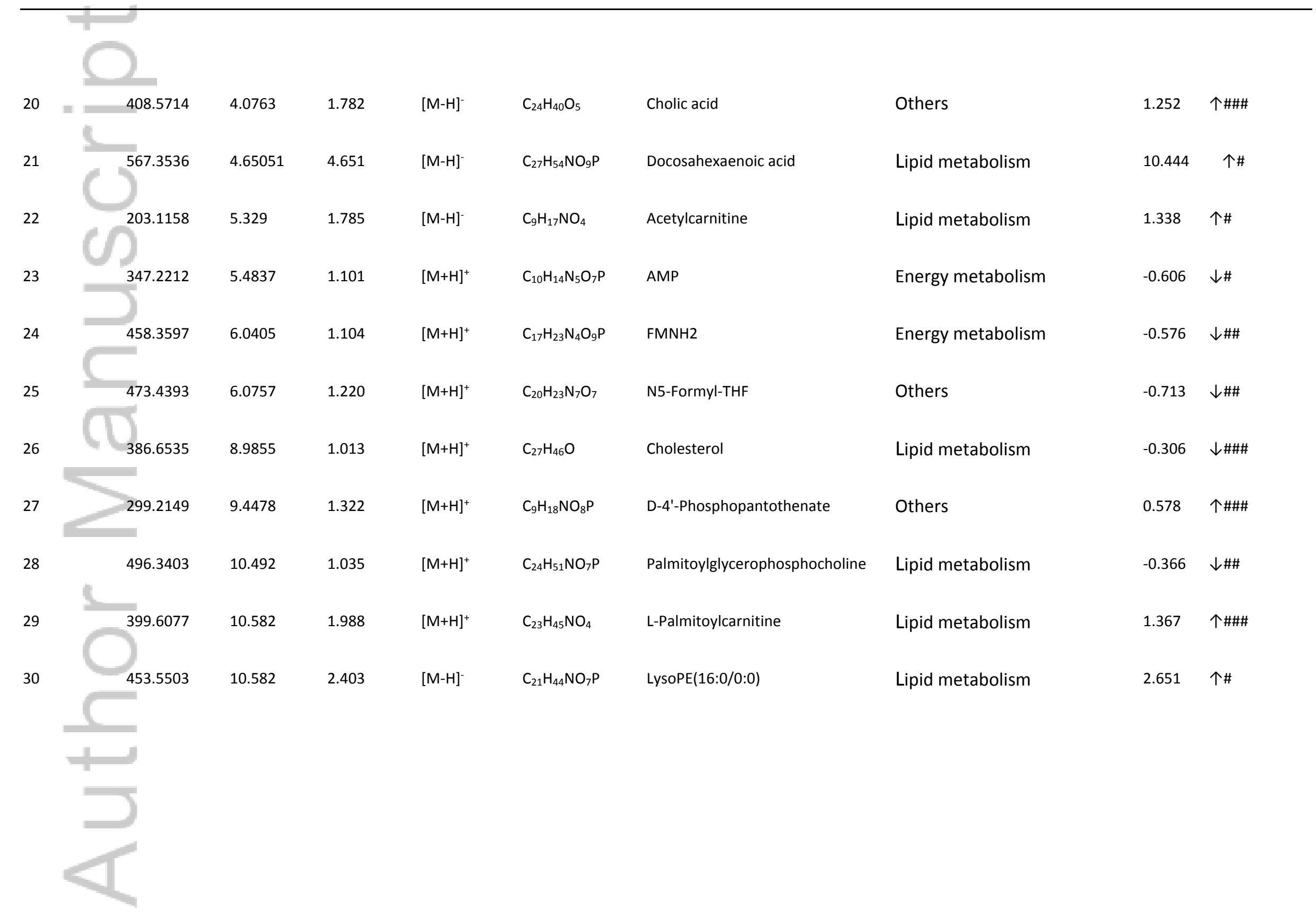

This article is protected by copyright. All rights reserved. 


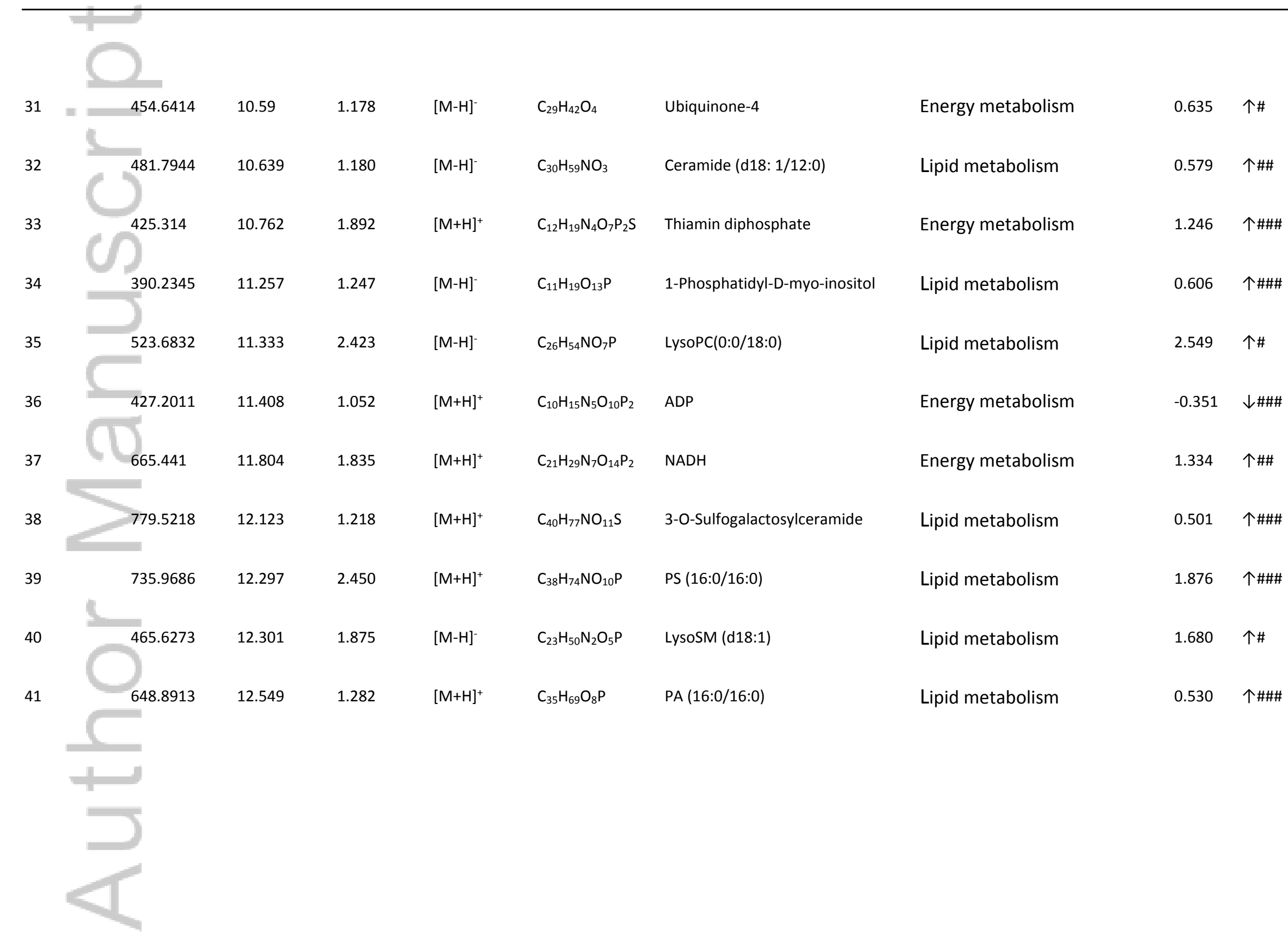

This article is protected by copyright. All rights reserved. 
$(\downarrow)$ : means decreased; (个): means increased.

$\#: P<0.05 ; \# \#: P<0.01 ; \# \#$ : $P<0.001$ (compared with control group);

CLs-cationic liposomes group, C-control group

Fold change was calculated as the logarithm of the average mass response (area) ratio between the two groups (Fold change=Log 2 [CLs/C])

This article is protected by copyright. All rights reserved. 


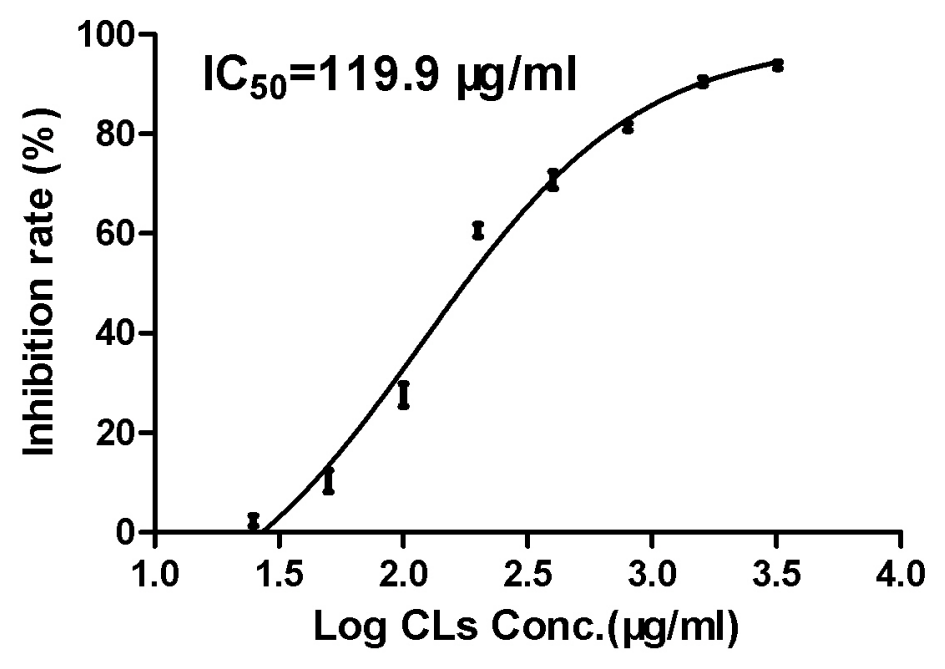

Fig 1. The inhibition rate of HepG2 cells treated with different concentrations of CLs.

This article is protected by copyright. All rights reserved. 

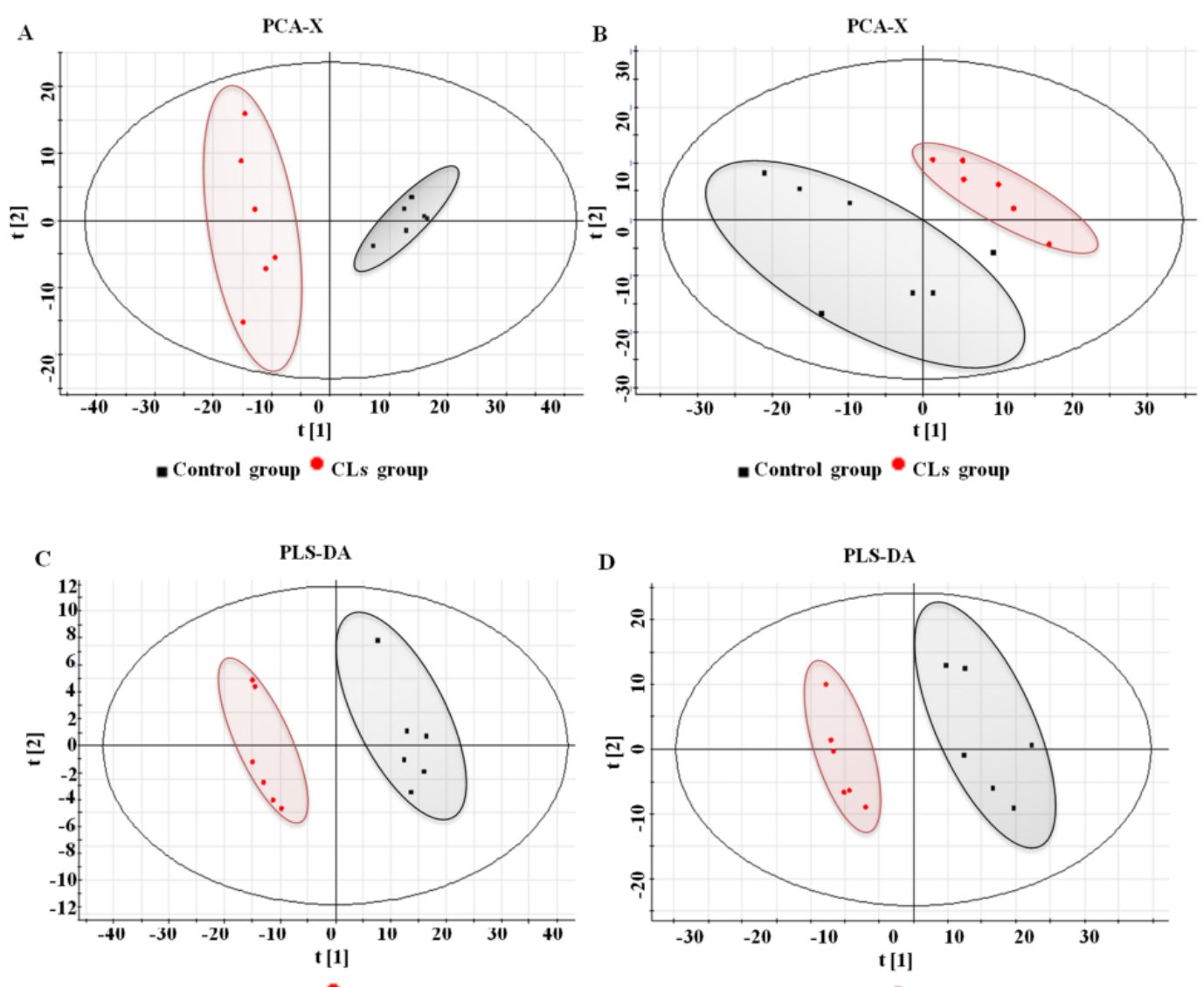

- Control group $\bullet \mathrm{CL}$ s group

- Control group $\bullet$ CLs group
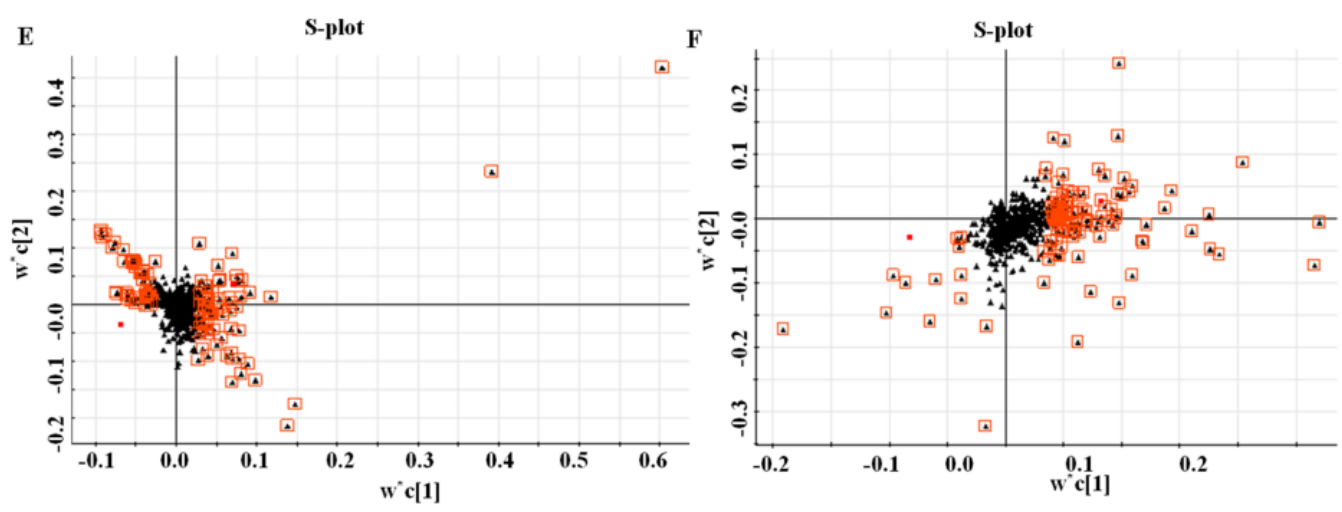

Fig 2. PCA scores, PLS-DA scores, S-plot between control and CLs groups in positive and negative mode. A: PCA score in positive mode $\left(R^{2} X=0.995, Q^{2}=0.793\right), B$ : PCA score in negative mode $\left(R^{2} X=0.982, Q^{2}=0.765\right), C$ : PLS-DA score in positive mode $\left(R^{2} X=0.855, R^{2} Y=0.998, Q^{2} Y=0.981\right), D$ : PLS-DA score in positive mode $\left(R^{2} X=0.926, R^{2} Y=0.999, Q^{2} Y=0.964\right)$, E: S-plot in negative mode, $F$ : S-plot in negative mode. 


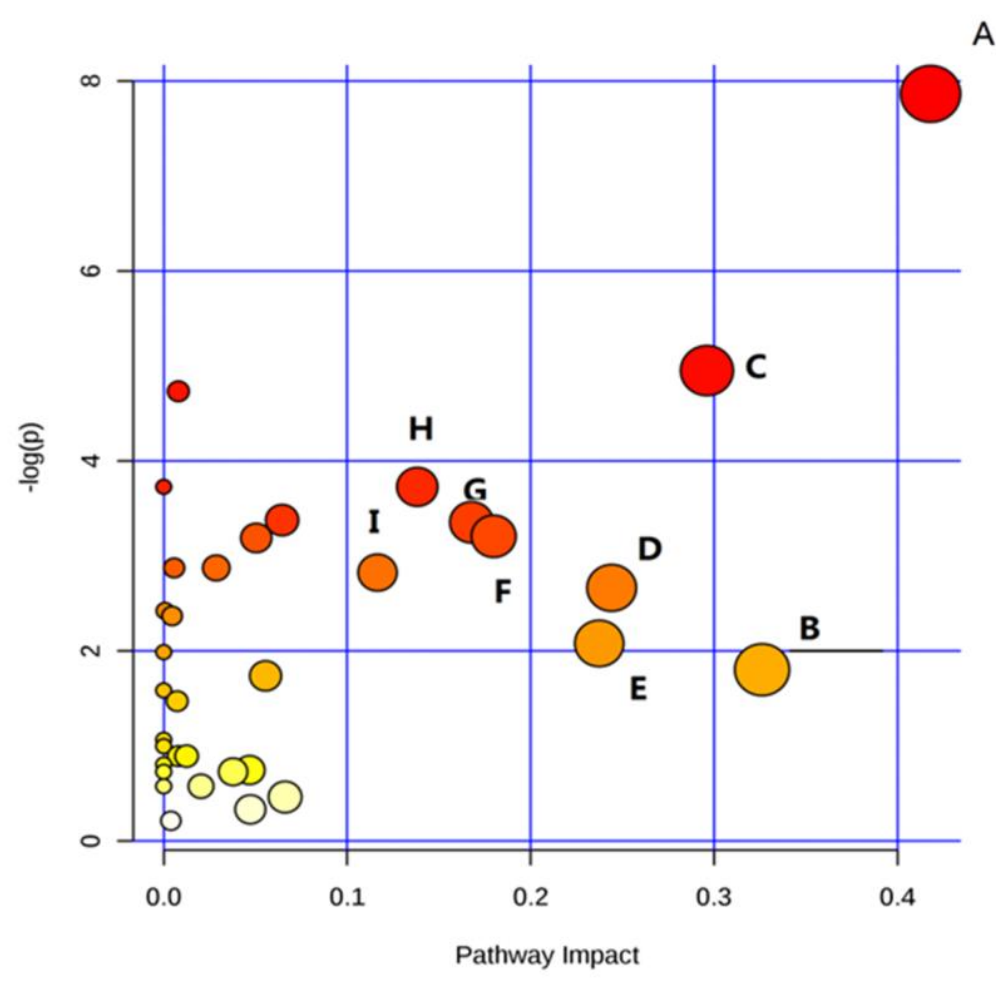

Fig 3. Impact on metabolic pathways suggested by the metabolites identified in HepG2 cells. (A) Arachidonic acid metabolism, (B) D-glutamine and D-glutamate metabolism, (C) Sphingolipid metabolism, (D) Pantothenate and CoA biosynthesis, (E) Glutathione metabolism, (F) TCA cycle, (G) Phenylalanine metabolism, (H) Glycerophospholipid metabolism, (I) Purine metabolism 


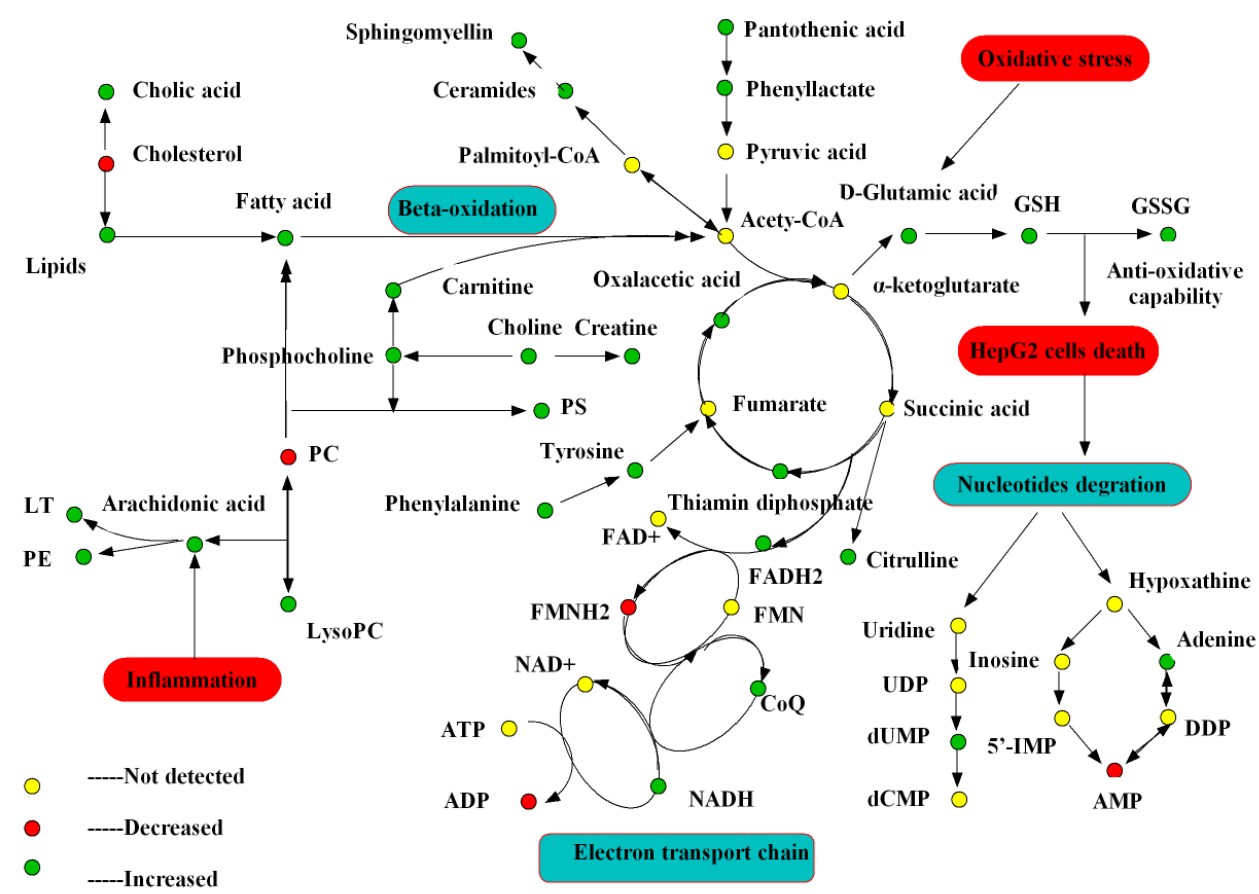

Fig 4. The network of metabolic pathways influenced by CLs in HepG2 cells. Identified differential metabolites in CLs group compared to the Control group are labeled in red (down-regulated) green (up-regulated) and yellow (not detected), respectively. 


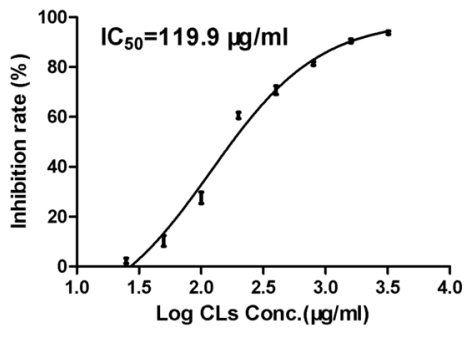

BMC_4036_F1.tif

This article is protected by copyright. All rights reserved. 

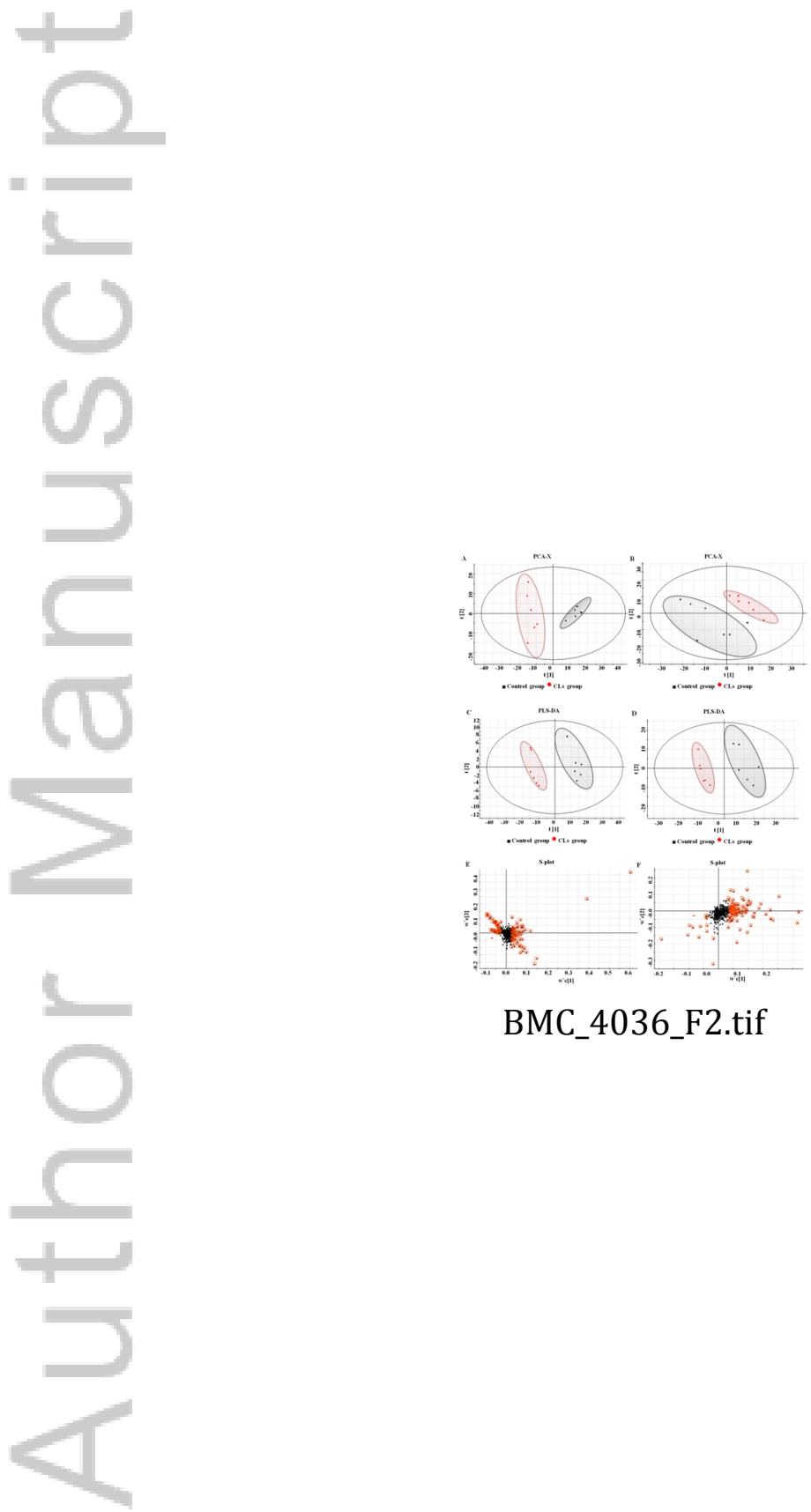

BMC_4036_F2.tif

This article is protected by copyright. All rights reserved. 

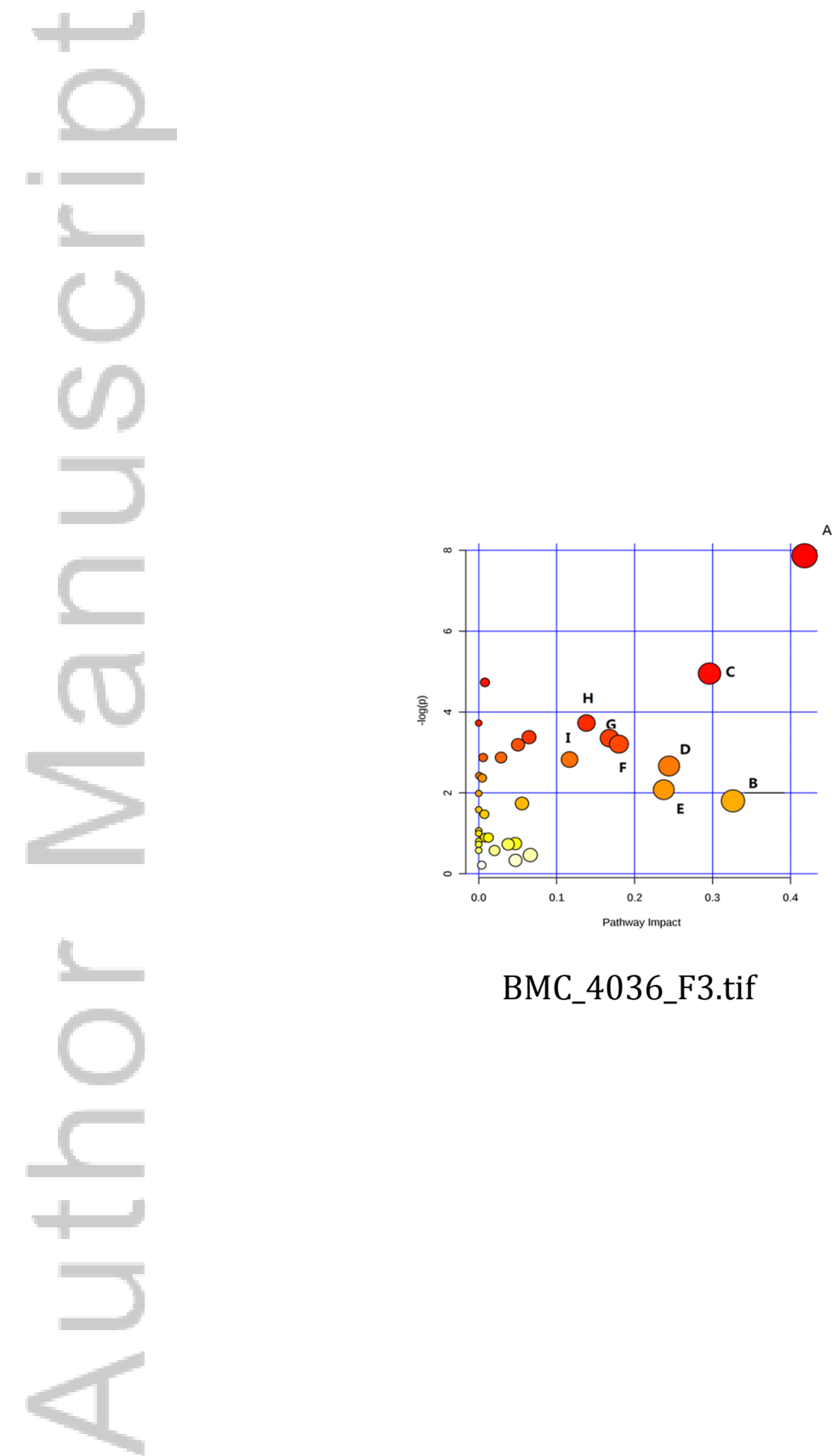

BMC_4036_F3.tif

This article is protected by copyright. All rights reserved. 

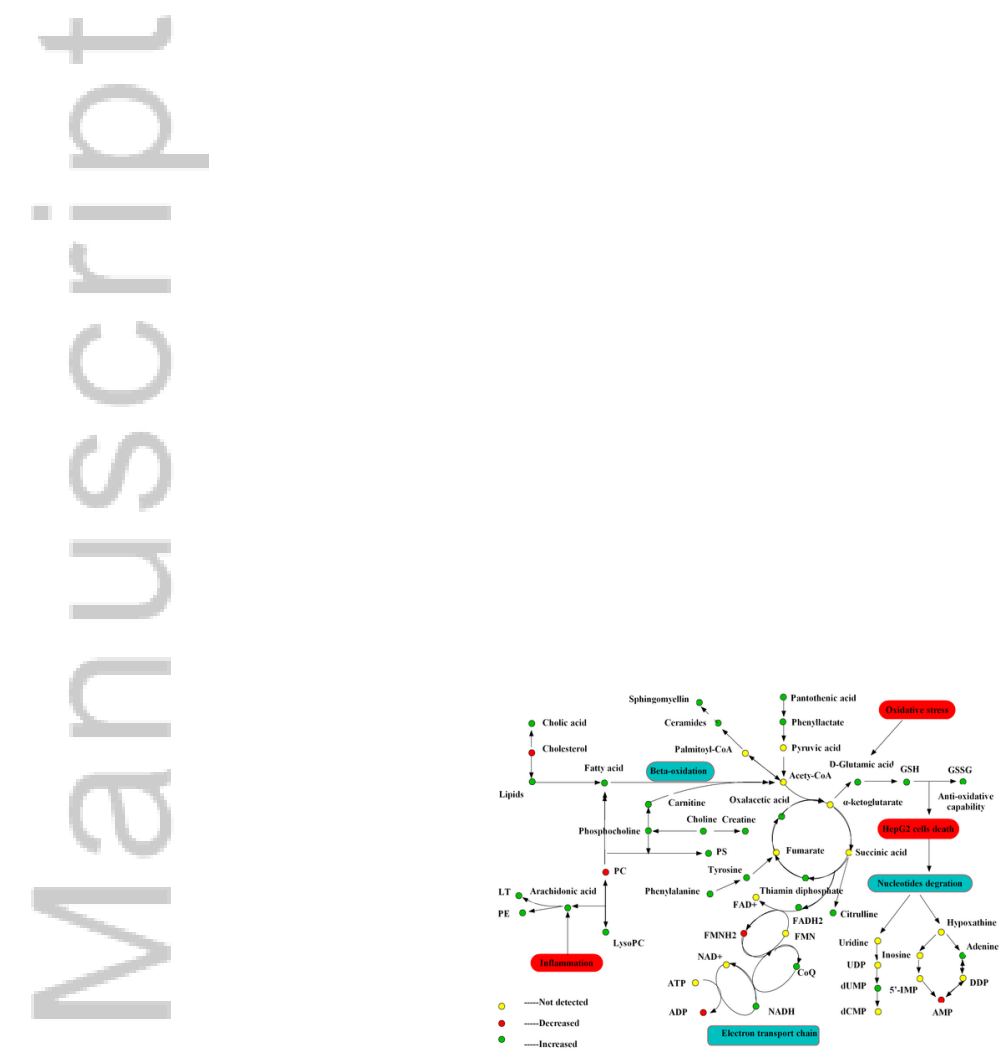

BMC_4036_F4.tif

This article is protected by copyright. All rights reserved. 